\title{
Technical note: Adjustment of all cow evaluations for yield traits to be comparable with bull evaluations
}

\author{
G. R. Wiggans, P. M. VanRaden, and T. A. Cooper \\ Animal Improvement Programs Laboratory, Agricultural Research Service, USDA, Beltsville, MD 20705-2350
}

\begin{abstract}
Traditional evaluations of cows with genotypes have been adjusted since April 2010 to be comparable with evaluations of bulls so that their value for estimation of single nucleotide polymorphism effects in genomic evaluation programs would be improved. However, that adjustment made them not comparable with traditional evaluations of nongenotyped cows. To create an adjustment for all cows with an evaluation based on US data, Mendelian sampling, which is the difference between predicted transmitting ability (PTA) and parent average (PA), was calculated for milk, fat, and protein yields and divided by a deregression factor. Standard deviations for the deregressed Mendelian sampling (DMS) were grouped by reliability with PA contribution removed $\left(\mathrm{REL}_{\text {no } \mathrm{PA}}\right)$. A multiplicative adjustment to reduce the DMS standard deviation for cows so that it would be the same as for bulls with similar $\mathrm{REL}_{\text {no }} \mathrm{PA}$ was represented as a linear function of $\mathrm{REL}_{\text {no PA }}$. Mean cow PA by birth year was subtracted from individual bull and cow PA to create within-year PA deviation groups, and mean DMS was calculated by PA deviation group. Means decreased for bulls and increased for cows with increasing deviation. The differences were fit by linear regression on PA deviation and used to adjust cow DMS. The adjustment reduced PTA of cows with a high PA and increased PTA of cows with a low PA but did not change estimated genetic trend because adjustment was within birth year. The adjustment also reduced variance of cow evaluations within birth year. Traditional evaluations of genotyped cows with a $\mathrm{REL}_{\text {no } \mathrm{PA}}$ of $\geq 55 \%$ were further adjusted so that the difference between those evaluations and direct genomic values calculated using only bulls as predictors was similar to that for bulls. The second adjustment was small compared with a 2010 adjustment and, therefore, had little effect on the comparability of evaluations for genotyped and nongenotyped cows. Cows with converted evaluations from other countries were excluded from
\end{abstract}

Received September 30, 2011.

Accepted February 2, 2012.

${ }^{1}$ Corresponding author: George.Wiggans@ars.usda.gov the predictor population, and their converted evaluations were adjusted so that the difference between their mean PTA and direct genomic value was the same as the corresponding difference for bulls. For cows with converted evaluations, the adjustment amount differed depending on $\mathrm{REL}_{\text {no PA }}(<55 \%$ or $\geq 55 \%)$. The new adjustment was implemented by USDA in April 2011 and permits a fairer comparison of estimated genetic merit between nongenotyped and genotyped cows.

Key words: cow evaluation, genomics, Mendelian sampling, parent average

\section{Technical Note}

To improve the accuracy of genomic evaluations, adjustment of traditional evaluations (TRAD) of cows for use in genomic evaluations was introduced in April 2010 (Wiggans et al., 2011). That adjustment reduced mean and variance of cow TRAD so that they would be similar to bull TRAD. Wiggans et al. (2011) showed that the adjustment improved accuracy of genomic evaluations. However, because the adjustment was applied only to genotyped cows and generally lowered their evaluations, it gave a benefit in ranking to nongenotyped cows. Representatives from the dairy industry requested that a method be developed that could be applied to all cows to restore comparability of cow evaluations, which was the objective of this research.

The TRAD from December 2010 for milk, fat, and protein yields for Holsteins $(9,107,506$ cows and 29,115 bulls), Jerseys (659,905 cows and 3,296 bulls), and Brown Swiss (93,871 cows and 798 bulls) born in 1995 or later were used to develop the adjustments. For cows, reliability (REL) of TRAD was required to be at least 3 percentage points higher than REL of parent average (PA).

\section{Adjustment of Standard Deviation of Deregressed Mendelian Sampling}

Variance of bull and cow TRAD were equalized based on adjustment of the standard deviation (SD) of deregressed Mendelian sampling (DMS). The DMS was calculated as the difference between PTA $_{\text {TRAD }}$ and 
$\mathrm{PA}_{\mathrm{TRAD}}$ for milk, fat, and protein yields, which was then divided by a deregression factor $\mathrm{R}$, where $\mathrm{R}=\mathrm{DE}_{\text {animal }}$ / $\left(\mathrm{DE}_{\text {animal }}+\mathrm{DE}_{\mathrm{PA}}+1\right)$, and $\mathrm{DE}=$ daughter equivalents for the animal (performance and progeny) or for PA (Wiggans et al., 2011).

To adjust $\mathrm{SD}_{\mathrm{DMS}}$ based on $\mathrm{REL}_{\mathrm{TRAD}}$, the relationship between $\mathrm{SD}_{\mathrm{DMS}}$ and $\mathrm{REL} \mathrm{L}_{\mathrm{TRAD}}$ with PA contribution removed $\left(\mathrm{REL}_{\text {no } \mathrm{PA}}\right)$ was estimated separately for bulls and cows within breed by the weighted quadratic regression

$$
\widehat{\mathrm{SD}}_{\mathrm{DMS}}=a+b_{1}\left(\mathrm{REL}_{\mathrm{noPA}}\right)+b_{2}\left(\mathrm{REL}_{\mathrm{noPA}}\right)^{2}+e,
$$

where $a$ is the intercept, $b_{1}$ and $b_{2}$ are regression coefficients, and $e$ is error; $a, b_{1}$, and $b_{2}$ were solved by minimizing the sum of

$$
w\left[\widehat{\operatorname{SD}}_{\mathrm{DMS}}-a-b_{1}\left(\mathrm{REL}_{\mathrm{noPA}}\right)-b_{2}\left(\mathrm{REL}_{\mathrm{noPA}}\right)^{2}\right]^{2},
$$

where $w$ is a weighting factor based on number of evaluations for that $\mathrm{REL}_{\text {no PA }}$. The ratio of bull $\widehat{\mathrm{SD}}_{\mathrm{DMS}}$ to cow $\widehat{\mathrm{SD}}_{\mathrm{DMS}}$ was fit as a linear regression on $\mathrm{REL}_{\text {no PA}}$ :

$$
\text { bull } \widehat{\mathrm{SD}}_{\mathrm{DMS}} / \text { cow } \widehat{\mathrm{SD}}_{\mathrm{DMS}}=\alpha+\beta_{1}\left(\mathrm{REL}_{\text {no PA }}\right)+e,
$$

where $\alpha$ is the intercept, $\beta_{1}$ is the slope, and $e$ is error. A linear regression was applied to represent the ratio because it gave adequate fit. For Holsteins, intercepts and slopes were similar for milk, fat, and protein yields; therefore, the intercept and slope for milk were used for all Holstein yield traits. Intercepts and slopes used to calculate variance adjustments for all breeds are given in Table 1. Those adjustments were applied multiplicatively to cow DMS with a ceiling of 1 for the multiplier:

$$
\operatorname{cow} \mathrm{DMS}_{\mathrm{adj}}=\left[\alpha+\beta_{1}\left(\mathrm{REL}_{\text {no PA }}\right)\right] \text { cow DMS, }
$$

where $\mathrm{DMS}_{\text {adj }}=$ DMS after variance adjustment and $\alpha+\beta_{1}\left(\mathrm{REL}_{\text {no PA }}\right) \leq 1$. Because DMS variance depends on $\mathrm{REL}_{\text {no }} \mathrm{PA}$, which is generally higher for bulls, this method was necessary to harmonize variance of cow and bull DMS.

\section{Adjustment of DMS Mean}

The DMS means were adjusted based on mean birthyear PA $\left(\overline{\mathrm{PA}}_{\mathrm{BY}}\right)$ for cows. Adjusting within birth year prevented the adjustment from affecting estimates of genetic trend. Individual PA deviations from cow $\overline{\mathrm{PA}}_{\mathrm{BY}}$ were grouped by ranges of $22.7 \mathrm{~kg}$ for milk and $2.27 \mathrm{~kg}$ for fat and protein separately for bulls and cows. Mean $\mathrm{DMS}_{\text {adj }}\left(\overline{\mathrm{DMS}}_{\mathrm{adj}}\right)$ was calculated for each PA-deviation group. The difference between cow and bull $\overline{\mathrm{DMS}}_{\text {adj }}$ was regressed on mean PA for the PA-deviation group:

$$
\text { cow } \overline{\mathrm{DMS}}_{\text {adj }}-\text { bull } \overline{\mathrm{DMS}}_{\mathrm{adj}}=\beta_{2}\left(\overline{\mathrm{PA}}_{i}\right)+e,
$$

where $\beta_{2}$ is a regression coefficient, $\overline{\mathrm{PA}}_{i}$ is the mean PA for PA-deviation group $i$, and $e$ is error. The regression was forced through the origin because estimated intercepts were close to zero. By doing so, the number of parameters required for implementation was reduced, and the slope could apply across traits. For Holsteins, coefficients were similar for yield traits; therefore, the milk coefficient was used for all Holstein traits. Coefficients for all breeds are in Table 2. Additive adjustment to $\mathrm{DMS}_{\mathrm{adj}}$ was this coefficient times PA deviation within birth year: $\beta_{2}\left(\mathrm{PA}-\overline{\mathrm{PA}}_{\mathrm{BY}}\right)$. The negative value for the multiplier $\left(\beta_{2}\right)$ increased PTA for cows with a PA below $\overline{\mathrm{PA}}_{\mathrm{BY}}$ and decreased PTA for cows with a PA above $\overline{\mathrm{PA}}_{\mathrm{BY}}$ (Figure 1). Adjusted PTA for both genotyped and nongenotyped cows (Figure 1) were generally similar to those of bulls with the same PA, with the greatest improvement observed for the highest and lowest PA. For cows with a $\mathrm{REL}_{\text {no PA }}$ of $>75 \%$, the adjustment was reduced to zero as $\mathrm{REL}_{\text {no }} \mathrm{PA}$ increased to recognize that a cow evaluation that includes contributions from many progeny approaches the characteristics

\begin{tabular}{|c|c|c|c|c|c|c|}
\hline $\begin{array}{l}\text { Yield } \\
\text { trait }\end{array}$ & \multicolumn{2}{|c|}{ Brown Swiss } & \multicolumn{2}{|c|}{ Holstein } & \multicolumn{2}{|c|}{ Jersey } \\
\hline$\overline{\text { Milk (kg) }}$ & $0.298 \pm 0.005$ & $1.516 \pm 0.015$ & $0.316 \pm 0.004$ & $1.433 \pm 0.014$ & $0.352 \pm 0.004$ & $1.366 \pm 0.011$ \\
\hline Protein $(\mathrm{kg})$ & $0.279 \pm 0.006$ & $1.517 \pm 0.019$ & $0.316 \pm 0.004$ & $1.433 \pm 0.014$ & $0.310 \pm 0.004$ & $1.415 \pm 0.013$ \\
\hline
\end{tabular}
of a bull evaluation.

After both variance and mean adjustment, adjusted yield deviation $\left(\mathrm{YD}_{\text {adj }}\right)$ was calculated as

Table 1. Intercepts and slopes ${ }^{1}$ for computing variance adjustments to deregressed Mendelian sampling of yield traits by breed

${ }^{1}$ Multiplied by reliability excluding contribution from parent average. 
Table 2. Multipliers (regression coefficients) of parent-average deviation from mean parent average within birth year to calculate additive adjustment to deregressed Mendelian sampling of yield traits by breed

\begin{tabular}{lccc}
\hline $\begin{array}{l}\text { Yield } \\
\text { trait }\end{array}$ & Brown Swiss & Holstein & Jersey \\
\hline Milk & $-0.298 \pm 0.095^{1}$ & $-0.434 \pm 0.011$ & $-0.204 \pm 0.031$ \\
Fat & $-0.466 \pm 0.108$ & $-0.434 \pm 0.011$ & $-0.259 \pm 0.031$ \\
Protein & $-0.468 \pm 0.066$ & $-0.434 \pm 0.011$ & $-0.220 \pm 0.035$ \\
\hline
\end{tabular}

${ }^{1}$ For Brown Swiss, the multiplier for fat yield was used as the multiplier for milk yield in application because the milk multiplier is quite different from those for fat and protein yields.

$$
\mathrm{YD}_{\text {adj }}=\mathrm{DMS}_{\mathrm{adj}}+\beta_{2}\left(\mathrm{PA}-\overline{\mathrm{PA}}_{\mathrm{BY}}\right)+\mathrm{PA} .
$$

The adjusted PTA $\left(\mathrm{PTA}_{\text {adj }}\right)$ for all US cows was PTA adj $=\mathrm{R}\left(\mathrm{YD}_{\mathrm{adj}}\right)+(1-\mathrm{R}) \mathrm{PA}_{\text {adj }}$, where $\mathrm{PA}_{\text {adj }}$ is $\mathrm{PA}$ calculated using PTA $_{\text {adj }}$ for the dam.

\section{Adjustment for Direct Genomic Values}

Evaluations of genotyped cows were further adjusted so that differences between their PTA $_{\text {adj }}$ and direct genomic values (DGV) had means similar to differences between PTA $\mathrm{TRAD}_{\mathrm{T}}$ and DGV for bulls. Because this

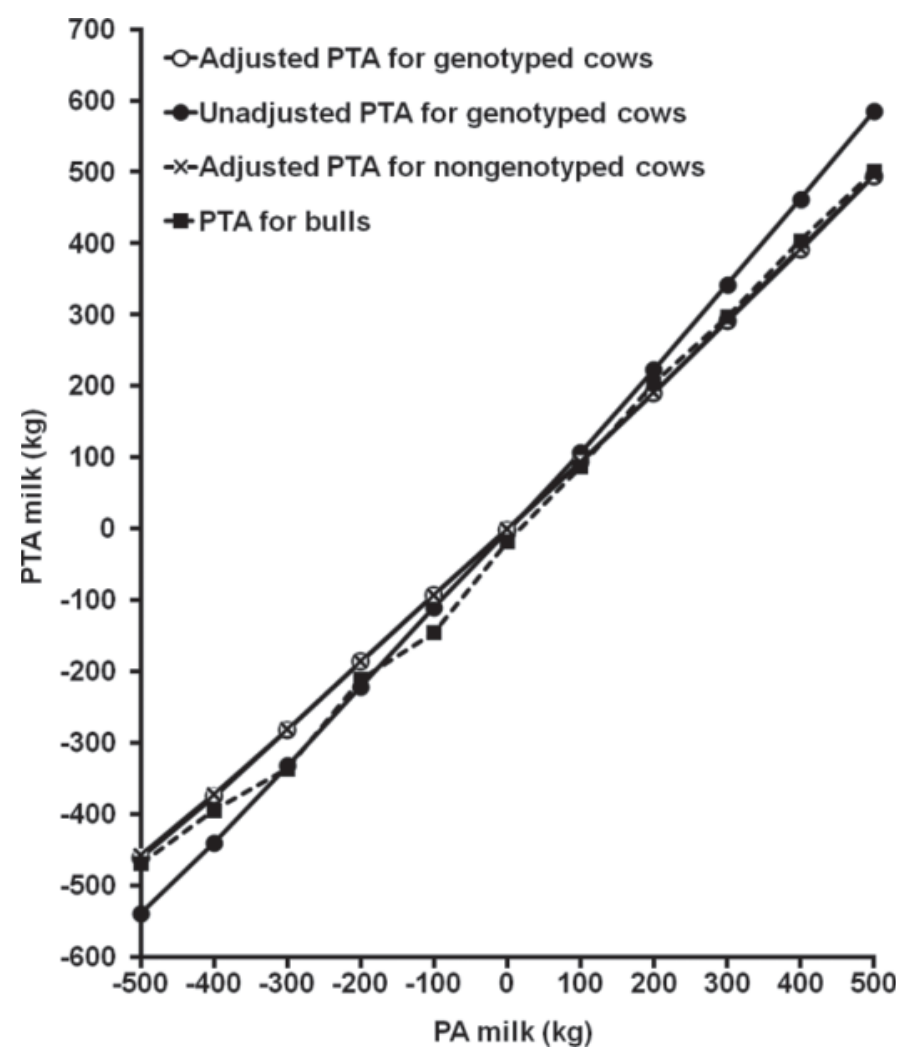

Figure 1. Holstein PTA for milk yield for animals born in 2005 by parent average (PA) for milk yield: genotyped cows with or without variance and mean adjustments of the traditional US evaluation, nongenotyped cows with variance and mean adjustment, and bulls. final adjustment was applied only to genotyped cows, it could reintroduce differences between genotyped and nongenotyped cows. However, the variance and mean adjustments for all cows reduced the magnitude of this final adjustment so that it may reflect, to some degree, bias in the evaluations of cows selected to be genotyped. This final adjustment represents a compromise between having comparable evaluations for all cows and making contributions to genomic evaluations comparable for cow and bull TRAD. The DGV was calculated as the sum of a cow's SNP and polygenic effects based only on a bull predictor population. Bulls in the predictor population (7,094 Holsteins and 1,401 Jerseys) were required to have genotypes and a PTA TRAD $_{\text {with }}$ REL of $<90 \%$. The REL restriction was imposed to eliminate bulls for which high REL had resulted in DGV that were forced to equal PTA. Table 3 contains the adjustment calculated from 1,303 Holstein and 335 Jersey cows with a $\mathrm{REL}_{\text {no PA }}$ of $\geq 55 \%$. No adjustment was required for cow $\mathrm{PTA}_{\text {adj }}$ with a $\mathrm{REL}_{\text {no PA }}$ of $<55 \%$. Adjustments for Jersey genotyped cows were used for Brown Swiss genotyped cows because of limited Brown Swiss data for calculating adjustments.

\section{Adjustment of Foreign Cow Evaluations}

Holstein evaluations from outside the United States, in particular Canada, have routinely been acquired to improve PA of US bull TRAD (VanRaden et al., 1995, 1999; Powell et al., 2000). With the advent of genomic evaluation, TRAD of genotyped females and dams of genotyped animals are collected in addition to the TRAD of bull dams (Wiggans, 2000). Different adjustments were required for cows with evaluations from

Table 3. Reductions of US traditional yield evaluations of cows with a reliability excluding contribution from parent average of $\geq 55 \%$ for calculating genomic evaluations by breed

\begin{tabular}{lcc}
\hline Yield trait & Holstein & Jersey $^{1}$ \\
\hline Milk $(\mathrm{kg})$ & 77.0 & 75.3 \\
Fat $(\mathrm{kg})$ & 3.8 & 2.9 \\
Protein $(\mathrm{kg})$ & 1.9 & 2.6 \\
\hline
\end{tabular}

${ }^{1}$ Also used for Brown Swiss. 
Table 4. Reductions of non-US Holstein cow evaluations for calculating genomic evaluations by reliability excluding contribution from parent average $\left(\mathrm{REL}_{\text {no PA }}\right)$

\begin{tabular}{lrr}
\hline & \multicolumn{2}{c}{$\mathrm{REL}_{\text {no PA }}(\%)$} \\
\cline { 2 - 3 } Yield trait & \multicolumn{1}{c}{$<55$} & \multicolumn{1}{c}{$\geq 55$} \\
\hline Milk $(\mathrm{kg})$ & 190.6 & 317.8 \\
Fat $(\mathrm{kg})$ & 6.9 & 11.7 \\
Protein $(\mathrm{kg})$ & 5.7 & 9.7 \\
\hline
\end{tabular}

other countries because foreign evaluation systems may have different properties and use different heritabilities than the US evaluation system. The variance and mean adjustments applied to all US cow evaluations were not applied to non-US cow evaluations. In addition, because of uncertainty about compatibility of non-US cow evaluations with bull evaluations, the non-US TRAD of cows (4,843 cows in April 2011) were not allowed to contribute to estimation of SNP effects as had been done previously (Wiggans et al., 2009). However, for genotyped non-US cows, an adjustment was necessary because their TRAD contribute to their genomic evaluations and the PA used in genomic evaluations of their progeny. Investigation of differences between Holstein DGV and PTA indicated that separate adjustments (Table 4) were necessary for non-US cow evaluations with a REL $_{\text {no PA }}$ of $<55 \%$ (3,011 non-US cows compared with 202 US and non-US predictor bulls) or $\geq 55 \%$ ( 573 non-US cows compared with 7,074 US and non-US predictor bulls). No adjustments were developed for non-US Jersey and Brown Swiss evaluations because of the small number of non-US cow evaluations included in genomic evaluations for those breeds.

The adjustment method was implemented by USDA in April 2011. Because the original cow adjustment in April 2010 (Wiggans et al., 2011) was not well understood by the dairy industry at the time of implementation, a coordinated effort was made to explain the new adjustment and document its effects (Cassell, 2011; Cassell and Wiggans, 2011).

Adjustment of cow TRAD was limited to yield traits because yield traits had the most severe problem. As discussed by Wiggans et al. (2011), abnormally large estimates of SNP effects in the pseudoautosomal region of the $\mathrm{X}$ chromosome are an indication of a discrepancy between evaluations of males and females. Some functional and type traits have large SNP effects in this region, which suggests that some adjustment might be warranted.

The adjustment of cow evaluations addresses a symptom of a problem in genetic evaluations. Determination of the reasons that cow evaluations are more extreme than bull evaluations is desirable. If those reasons were known, evaluation systems could be modified to address them. The TRAD systems will need to be modified to account for bias due to genomic selection. Simultaneous estimation of TRAD and genomic evaluations using a single-step method to combine phenotypic, pedigree, and genomic information (e.g., Misztal et al., 2009) might solve the problem of selection bias but would require a different solution to the problem of lack of comparability between cow and bull evaluations.

\section{ACKNOWLEDGMENTS}

The authors recognize contributions from J. P. Chesnais (Semex Alliance, Ottawa, Ontario, Canada), who provided suggestions and advice on the project. The roles of dairy records processing centers (AgriTech Analytics, Visalia, CA; AgSource Cooperative Services, Verona, WI; Dairy Records Management Systems, Raleigh, NC, and Ames, IA; and DHI Computing Services, Provo, UT) in supplying the data supporting genetic evaluations, and of S. M. Hubbard (Animal Improvement Programs Laboratory, ARS, USDA, Beltsville, MD) in reviewing the manuscript are also acknowledged.

\section{REFERENCES}

Cassell, B. 2011. Cow PTAs to get more adjustments in April. Hoard's Dairyman 156:222-223.

Cassell, B., and G. Wiggans. 2011. Adjustments make all cow PTAs similar to those on genomically tested cows. Holstein Association USA press release, Mar. 7, 2011. Accessed Sep. 14, 2011. http:// www.holsteinusa.com/pdf/USDA_Update_nr2011.pdf.

Misztal, I., A. Legarra, and I. Aguilar. 2009. Computing procedures for genetic evaluation including phenotypic, full pedigree, and genomic information. J. Dairy Sci. 92:4648-4655.

Powell, R. L., H. D. Norman, and G. Banos. 2000. Improving prediction of national evaluations by use of data from other countries. J. Dairy Sci. 83:368.e1-368.e10.

VanRaden, P. M., R. L. Powell, G. R. Wiggans, and H. D. Norman. 1995. Changes in USDA-DHIA genetic evaluations (July 1995). AIPL Res. Rep. CH4(7-95). Accessed Sep. 15, 2011. http://aipl. arsusda.gov/reference/changes/chng957.pdf.

VanRaden, P. M., G. R. Wiggans, and C. P. Van Tassell. 1999. Changes in USDA-DHIA genetic evaluations (February 1999). AIPL Res. Rep. CH13(2-99). Accessed Sep. 15, 2011. http://aipl.arsusda. gov/reference/changes/chng9902.html.

Wiggans, G. 2000. Foreign evaluations requested for more cow dams. AIPL Changes to Evaluation and Editing System-February 2000. Accessed Sep. 15, 2011. http://aipl.arsusda.gov/reference/changes/chng0002.html.

Wiggans, G. R., T. A. Cooper, P. M. VanRaden, and J. B. Cole. 2011. Technical note: Adjustment of traditional cow evaluations to improve accuracy of genomic predictions. J. Dairy Sci. 94:61886193.

Wiggans, G. R., T. S. Sonstegard, P. M. VanRaden, L. K. Matukumalli, R. D. Schnabel, J. F. Taylor, J. P. Chesnais, F. S. Schenkel, and C. P. Van Tassell. 2009. Genomic evaluations in the United States and Canada: A collaboration. ICAR Tech Ser. 13:347-353. 